\title{
Workshop on the Current Status and Future of Underwater Hearing Research
}

\author{
Dorian S. Houser \\ National Marine Mammal Foundation \\ 2240 Shelter Island Drive, \#200 \\ San Diego, CA 92107 \\ phone: (877) 360-5527 ext.112 fax: (877) 773-3153 email: dorian.houser@nmmpfoundation.org \\ Award Number: N000141310263 \\ http://www.nmmf.org/

\section{LONG-TERM GOALS} \\ An assessment of the current state of research on marine mammal is needed in order to evaluate the \\ contributions of current research programs to meeting data gaps, the return on investment of current \\ programs, and the ability to meet outstanding data needs given the current state of technology and \\ access to marine mammals. The assessment supports the long-term goal of an understanding of \\ research progress and future research potential by providing a comprehensive, externally reviewed \\ critique of the state of the art in marine mammal hearing research.
}

\section{OBJECTIVES}

The objective of the workshop is to assess the current state of knowledge in key topic areas of mammalian underwater hearing; evaluate on-going research efforts and identify strengths and weaknesses; and formulate recommendations for future research based on current knowledge and its potential for advancement based on available research methods.

\section{APPROACH}

A list of active marine mammal hearing reseasrchers will be created, both foreign and domestic, based on the applicability of each individual's contributions to research in marine mammal hearing. The researchers will be invited to present on their recent and current research efforts at a small venue that facilitates group discussion. Presentations will be made over a three-day period. Presentations will be grouped according to research topics and discussion periods will be held at the end of each topic session. Research topics to be addressed include the following: temporary threshold shift (TTS), masking, hearing and echolocation, auditory weighting functions, evoked potential audiometry, and anatomical models.

Experts in the topic areas, but which do not work with marine mammals, will be selected to serve as external reviewers. Attempts will be made to select two scientists from academia as well as one scientist from the National Oceanic and Atmospheric Association (NOAA) that can evaluate the presentations for their scientific merit, potential for growth, and possible benefit to improving understanding of the impact of anthropogenic sound on marine mammals. The external reviewers will 


\section{Report Documentation Page}

Form Approved

OMB No. 0704-0188

Public reporting burden for the collection of information is estimated to average 1 hour per response, including the time for reviewing instructions, searching existing data sources, gathering and maintaining the data needed, and completing and reviewing the collection of information. Send comments regarding this burden estimate or any other aspect of this collection of information,

including suggestions for reducing this burden, to Washington Headquarters Services, Directorate for Information Operations and Reports, 1215 Jefferson Davis Highway, Suite 1204, Arlington

VA 22202-4302. Respondents should be aware that notwithstanding any other provision of law, no person shall be subject to a penalty for failing to comply with a collection of information if it

does not display a currently valid OMB control number.

1. REPORT DATE

30 SEP 2014

4. TITLE AND SUBTITLE

Workshop on the Current Status and Future of Underwater Hearing Research

6. $\operatorname{AUTHOR}(\mathrm{S})$

7. PERFORMING ORGANIZATION NAME(S) AND ADDRESS(ES)

National Marine Mammal Foundation,2240 Shelter Island Dr, Suite 200,San Diego,CA,92106

9. SPONSORING/MONITORING AGENCY NAME(S) AND ADDRESS(ES)

3. DATES COVERED

00-00-2014 to 00-00-2014

5a. CONTRACT NUMBER

5b. GRANT NUMBER

5c. PROGRAM ELEMENT NUMBER

5d. PROJECT NUMBER

5e. TASK NUMBER

5f. WORK UNIT NUMBER

8. PERFORMING ORGANIZATION REPORT NUMBER

10. SPONSOR/MONITOR'S ACRONYM(S)

11. SPONSOR/MONITOR'S REPORT NUMBER(S)

12. DISTRIBUTION/AVAILABILITY STATEMENT

Approved for public release; distribution unlimited

13. SUPPLEMENTARY NOTES

14. ABSTRACT

15. SUBJECT TERMS

16. SECURITY CLASSIFICATION OF:

a. REPORT

unclassified b. ABSTRACT

unclassified c. THIS PAGE

unclassified
17. LIMITATION OF ABSTRACT

Same as

Report (SAR)
18. NUMBER 19a. NAME OF

OF PAGES RESPONSIBLE PERSON

3

Standard Form 298 (Rev. 8-98) Prescribed by ANSI Std Z39-18 
evaluate the current state of knowledge (and associated data needs), assess how research results have met critical data gaps, and formulate recommendations for future research based on the current state of knowledge and the most promising research avenues.

A report of the workshop synthesizing the analysis of the reviewers will be made publicly available following the workshop. The report will address the current state of underwater hearing research in the selected topics and provide recommendations for future research, based on scientific merit and application relevance.

\section{WORK COMPLETED}

An organizing committee was established to act as a steering group for planning the workshop. Subsequently, an initial invitee list was created and invitations sent to prospective attendees based upon their contributions to the research topics to be covered. All but two of the invited researchers agreed to attend the meeting. External reviewers were recruited from the fields of TTS research, auditory evoked potential studies, and marine mammal acoustic ecology. Specifically, Drs. Colleen Le Prell (University of Florida), Robert Burkard (University at Buffalo), and Sofie Van Parijs (NMFS) agreed to serve.

The Best Western Island Palms Hotel was selected as the workshop venue and a date of September 1012 was selected for the workshop dates. Read-ahead materials were requested from all presenters prior to the meeting to enable the external reviewers to become familiar with the research topics. Readahead materials were provided to the reviewers in July and August, 2013. Presenters were permitted to bring one additional person with them, preferrably a professional in the field and which could contribute to the discussion and evaluation of the research topics.

The workshop was held on September 10-12 and was attended by 31 people, including presenters, additional invitees, reviewers, regulators and program managers. A post-meeting discussion was held by the conference organizers and reviewers after the conclusion of the last set of talks. The meeting was held to organize and plan for the report on the workshop, which was anticipated to be produced prior to the close of calendar year 2013.

All external reviewer reports were received by the end of November 2013. The reviewer evaluations were consolidated and synthesized into a draft report that included an evaluation of the state of each field of research as well as recommendations for future reseach. The draft report was returned to the reviewers for editing in march of 2014. Final edits were received by the end of April and the final report was published in May 2014.

The report entitled, "Report on the Current Status and Future of Underwater Hearing Research," was printed in hard-copy and made available to the public via PDF. The report was advertised on the MARMAM list-server and posted on the National Marine Mammal Foundation website for download (http://nmmf.org/resources/publications/).

\section{RESULTS}

Discussion outcomes and extenal reviewer input highlighted several opportunities for research advancement, mechanisms for improving comparability of research results across facilities, and points of research that may or may not require continued work. In the area of temporary threshold shift 
studies, the potential for PTS from single-event exposures to anthropogenic sound sources was deemed low and methods for understanding how cumulative effects of TTS might lead to auditory system degradation were recommended for future research. In regard to characterizing damage that may not be manifest in behavioral or electrophysiological measures of hearing sensitivity, it was recommended that a discussion of the utility of stranded marine mammals slated for euthanasia be explored as a model system for investigation. With respect to auditory evoked potential (AEP) methodologies, standardization of methodologies was recommended as a means for improving the comparability of results between different laboratories. In addition, deeper exploration of variability in click-evoked response waveforms and input/output functions were recommended as a means of investigating degradation in the auditory system that might not be reflected via auditory thresholds alone. Reviewers recommended that "expert" animals be utilized to guide AEP studies and validate anatomical model outputs by employing AEP methods and psychophysical (behavioral) methods in the same animals. Collaboration and cross-fertilization of research efforts was encouraged.

\section{IMPACT/APPLICATIONS}

The meeting will broaden the current state of knowledge regarding marine mammal hearing and the impacts of anthropogenic sound on marine mammals through consolidation and synthesis of the most recent and emerging research results. The review and research recommendations provided by the independent review panel will provide regulatory and research agencies with a better understanding of the state of science as it relates to environmental compliance issues. The conference report will provide a synthesis of the current state of hearing research for academia, government, industry, and interested members of the public.

\section{PUBLICATIONS}

Houser, DS and Moore, PW. Report on the Current Status and Future of Underwater Hearing Research. Report No. NMMF-001-14, National Marine Mammal Foundation, San Diego, CA. [published] 